Article

\title{
Dust Storm Remote Sensing Monitoring Supported by MODIS Land Surface Reflectance Database
}

\author{
Ke Sun ${ }^{1}$, Qinghua Su ${ }^{2,3, *}$ and Yanfang Ming ${ }^{3}$ \\ 1 Institute of Earthquake Forecasting, China Earthquake Administration, Beijing 100036, China \\ 2 School of Geography and Tourism, Qufu Normal University, Qufu 273165, China \\ 3 Geomatics College, Shandong University of Science and Technology, Qingdao 266590, China \\ * Correspondence: suqinghua@qfnu.edu.cn; Tel.: +86-0532-8803-2922
}

Received: 27 June 2019; Accepted: 23 July 2019; Published: 27 July 2019

\begin{abstract}
MODIS (Moderate Resolution Imaging Spectroradiometer) land product subsets can provide high-quality prior knowledge for the quantitative inversion of land and atmospheric parameters. Using the LSR (Land Surface Reflectance) dataset, dust storm remote sensing monitoring in this study was carried out via quality control and data synthesis. A dynamic threshold supported dust storm monitoring method was proposed based on a monthly synthesized LSR database, which is produced using MOD09A1 data. The apparent reflectance of clear-pixels with different atmospheric conditions was simulated by the radiative transfer model. A pixel can be identified as a dust pixel if the apparent reflectance is larger than that of the simulated data. The proposed method was applied to the monitoring of four dust storms, the results of which were evaluated and analyzed via visual interpretation, MICAPS (Meteorological Information Comprehensive Analysis and Process System), and the OMI AI (Ozone Monitoring Instrument Aerosol Index) with the following conclusions: the dust storm monitoring results showed that most of the dust areas could be accurately detected when compared with the true color composite images, and the dust monitoring results agreed well with the MICAPS observation station data and the OMI AI dust products.
\end{abstract}

Keywords: LSR database; dust storms; dynamic threshold; remote sensing

\section{Introduction}

Dust storms refer to strong winds that roll up a large amount of sand and dust from the ground and make the horizontal visibility less than $1 \mathrm{~km}$. They have the characteristics of sudden occurrence and short duration. Dust storms are a severe regional weather phenomena that has extremely destructive effects on the ecosystem. They can not only accelerate soil desertification and cause serious atmosphere pollution, but can also result in a negative influence on human health, agricultural production, transportation, and communication, and have feedback effects on regional and global climate change by interfering with ocean biogeochemistry such as the iron and nitrogen cycle to the oceans [1-6]. Primary research methods for dust storms include remote sensing monitoring and surface observations [7]. Since the surface observations are sparsely distributed, especially in desert areas and adjacent arid and semi-arid areas, it is difficult to determine the dust source regions and the transport pathways. With multi-source, dynamic, current, and accurate properties, satellite remote sensing technology has the characteristics of wide coverage, continuous space, and fast and dynamic observation, which can play an important role in dust storm monitoring. With the rapid development of satellite remote sensing technology, dust storm remote sensing monitoring has been widely used for monitoring, tracking, forecasting, and disaster assessment [8-10].

Dust storm monitoring mainly uses the difference of the reflectance between dust and the typical surface or the cloud in the visible, near infrared bands and brightness temperature in the thermal 
infrared bands, and sets appropriate thresholds to distinguish dust pollution pixels from clear pixels or cloudy pixels. Under cloudless conditions, the reflectance of dust storm in visible and near infrared bands is much different with the typical surface because of the strong scattering characteristics of dust storm. Di et al. analyzed the radiance response characteristics of the Indian National Satellite (INAAT) 3D, and built the Enhanced Dust Index (EDI) for dust identification via apparent reflectance at $0.65 \mu \mathrm{m}$ (visible band) and $1.63 \mu \mathrm{m}$ (short-wave infrared band) [11]. Yang et al. used the reflectance threshold of blue band to detect the dust from the clear pixels [12]. Because of the scattering difference caused by particle size and the absorption difference caused by water content, there are obvious radiation differences between dust storm and cloud in visible and near infrared bands. Roskovensky and Liou used the reflectance of $0.54 \mu \mathrm{m}, 0.65 \mu \mathrm{m}, 0.86 \mu \mathrm{m}, 1.38 \mu \mathrm{m}$ to study the difference between the dust storm and cirrus clouds, and proposed an effective method for detecting dust storm from cirrus [13]. The information in visible and near infrared bands has been widely used in dust storm monitoring from different sensors, but the information obtained in such wavelength is significantly affected by the surface composition, especially in areas covered by thin dust storm. Due to the complexity of surface spectral features, it is very difficult to set the appropriate threshold to distinguish all types of surface and different characteristics of dust storm, so the stability of this method is relatively poor.

The scattering of large particles in the dust storm results in a negative brightness-temperature difference in the wavelength range of 10 to $12 \mu \mathrm{m}$. Typically, the $11 \mu \mathrm{m}$ brightness temperature of dust storms is lower than the $12 \mu \mathrm{m}$ brightness temperature; whereas the typical surface brightness temperature is the opposite. Therefore, dust storm detection with infrared bands has been adopted multiple satellite sensors with the methods of thermal infrared split windows (11 and $12 \mu \mathrm{m}$ channels), etc. $[14,15]$. Ackerman monitored dust storms occurring over the Arabian Peninsula, Africa, and the Southwest United States based on the brightness temperature difference between $11 \mu \mathrm{m}$ and $1 \mu \mathrm{m}$ and proved that the negative difference between $11 \mu \mathrm{m}$ and $12 \mu \mathrm{m}$ is helpful to detect and track sandstorms [16]. Using the 16 AIRS (Atmospheric Infrared Sounder) observation channels observations data in the thermal infrared region, $\mathrm{Xu}$, et al. developed a DSSI (Dust Spectral Similarity Index), which was calculated from the accumulated brightness temperature differences, to detect the dust storm, and used for several Asia dust events observed in northern China, results shows it can reach a high accuracy [17]. However, such methods are not stable and are influenced by many factors, which often cause huge misidentification for dust scenes. For example, it has been reported that water cloud often displays a similar spectrum with dust storm in the split window channels [15]. Moreover, some thermal infrared bands are affected by other factors, such as the application of $8.6 \mu \mathrm{m}$ bands is susceptible to the influence of $\mathrm{SO}_{2}$ absorption [18].

Although many kinds of dust storm detection methods have been developed, but it is still difficult to achieve high accuracy whether it is based on visible near infrared band, thermal infrared band, or combination of the two kinds of bands. The main reason is the complexity of the surface structure and the diversity of dust characteristics. Most of the existing detection methods are based on fixed threshold method to distinguish dust storm from typical surface and cloud-covered areas. When thin dust storm covered over different surface types, mixed pixels consisting of surface and dust may have very complex radiation characteristics that make it difficult to distinguish between them by using fixed thresholds in limited bands or band combinations [19]. The main reason for the above problems is that the surface features are unknown, otherwise, the dust contaminated pixels can be identified according to the change in the radiation from the dust to the surface.

Aimed toward alleviating the shortcomings of the fixed threshold method, Liu et al. developed a dynamic reference brightness temperature differences (DRBTD) algorithm to improve the dust detection. Using long-term MODIS data, the linear relationship between the brightness temperature of the 12 and $11 \mu \mathrm{m}$ channels and brightness temperature of 8.6 and $11 \mu \mathrm{m}$ channels in clear sky was analyzed. The dust detection thresholds are dynamically generated according to the observed brightness temperatures [20]. The application of this method is limited by the dependence on long time clear sky conditions and the need for surface stability in a long time range. In order to 
determine the suitable dust identification methods for different regions, the spatial distribution of background BTD in mainland China was analyzed by She et al., and the dust identification thresholds of brightness temperature difference were determined according to the characteristic of the land surface reflectance [21]. This method effectively improves the detection accuracy of dust storms, but its spatial adaptability is limited due to the complex relationship between reflectance in short wave band and brightness temperature in thermal infrared band.

Based on the above problems, a dynamic threshold method for dust monitoring supported by surface reflectance products was proposed in this paper. Surface reflectance data were obtained by using $1000 \mathrm{~m}$ resolution surface reflectance products of a long time series to support dust monitoring. With the support of surface reflectance, the possible range of satellite reflectance under cloud-free and dust-free conditions can be calculated, and the threshold related to surface reflectance can be set to identify dust. The first part of this paper describes a brief review of the topic and previous research performed in this area; the second part presents the process of atmospheric radiation transmission, the spectral characteristics of dust and a typical surface, the generation process of the surface reflectance database, and the method of dynamic threshold of dust identification; the third part tests and verifies the four dust storms processes. Finally, the main work and results of this paper and the main problems are introduced.

\section{Methods}

\subsection{Principles}

\subsubsection{Atmospheric Radiation Transfer}

Radiance received by remote sensor in the visible to NIR (Near Infrared) band can be described as

$$
L\left(\tau_{a}, \mu_{s}, \mu_{v}, \phi\right)=L_{0}\left(\tau_{a}, \mu_{s}, \mu_{v}, \phi\right)+\frac{\rho}{1-S\left(\tau_{a}\right) \cdot \rho} \cdot F_{d}\left(\tau_{a}, \mu_{s}\right) T\left(\tau_{a}, \mu_{v}\right)
$$

where $L$ is the total radiance received by the satellite sensor; $L_{0}$ is the atmospheric path radiation; $\tau_{a}$ is the AOD (Aerosol Optical Depth); $\mu_{s}$ and $\mu_{v}$ are the cosine of the solar and observation zenith angles; $\phi$ is the relative azimuth of the sensor and the sun; $\rho$ is the surface reflectance; $S$ is the atmospheric backscattering ratio; $F_{d}$ is the downward total radiation to the land surface; and $T$ is the transmissivity between the land surface and satellite sensor.

It can be seen from Equation (1) that the signals received by the satellites are the result of the combined action of the Earth's surface and the atmosphere. If dust in the air covers different types of surfaces, its pixel reflectance will be different. It is difficult to distinguish dust from the surface pixels by a single threshold. Moreover, the intensity of dust also affects the signal received by the satellites.

Apparent reflectance is usually used in dust monitoring, which can be calculated by

$$
\rho^{*}=\frac{\pi \times L \times d^{2}}{E S U N \times \cos \theta}
$$

where $d$ is the mean Earth-Sun distance; ESUN is the solar flux at the top of the atmosphere; and $\theta_{S}$ is the solar zenith angle.

\subsubsection{Spectrum Properties of Dust Storms and the Typical Land}

Radiation difference is the main basis for distinguishing dust from the surface. To study the spectral properties of dust and other surface objects, pixels of thick dust, thin dust, cloud, snow/ice, desert/Gobi, and vegetation were selected from the images of several dust storm events from 2013 to 2016 in Western and Northern China. Figure 1 shows the spectrum of different targets at MODIS bands 1-7. This shows that cloud and snow/ice possessed high reflectance in the visible and NIR band, and that dust reflectance was higher than the vegetation, and lower than the cloud and snow/ice; 
moreover, the reflectance of desert/Gobi was obviously lower than thick dust, but was similar to thin dust. According to the reflectance difference, a fixed threshold could be set to separate dust from other land objects. However, the reflectance of real remote sensing images is much more complex than the spectral features shown in Figure 1. Most pixels are mixed pixels, and the spectral information of one pixel is the compound information of several land objects. The reflectance of the mixed pixel is determined by all of the components in the pixel and can be described by the function of the product of the respective objects' spectrum and their respective proportions [19,22,23]. However, it is difficult to achieve the high-precision detection of dust by using the simple fixed threshold method. The main reason is that the surface reflection characteristics are unknown. A fixed threshold cannot identify dust above different surface types with a unified standard. In order to solve this problem, this paper proposed using the existing surface reflectance database to provide the prior knowledge of the surface, and on this basis, to identify dust.

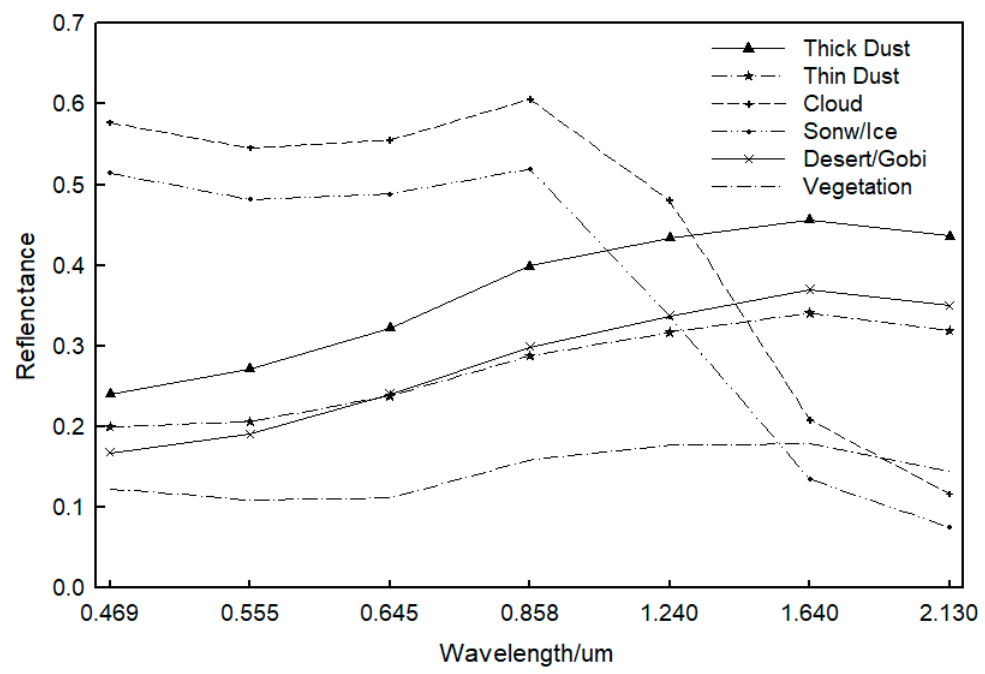

Figure 1. The spectrum of different targets at MODIS bands 1-7.

\subsection{Land Surface Reflectance Data Set Construction}

Due to the high quality of MOD09 (MODIS Surface Reflectance) products, they have been used as important prior data for quantitative inversion of land and atmospheric parameters from satellite data. Table 1 shows the description of MOD09 products.

Table 1. MOD09 product description (Collection 5).

\begin{tabular}{cccc}
\hline Name & Description & Pixel Size & Temporal Granularity \\
\hline MOD09GQ & MODIS band 1-2 daily surface reflectance & $250 \mathrm{~m}$ & Daily \\
MOD09GA & MODIS band 1-7 daily surface reflectance & $500 \mathrm{~m}, 1 \mathrm{~km}$ & Daily \\
MOD09Q1 & MODIS band 1-2 surface reflectance & $250 \mathrm{~m}$ & 8-Day \\
MOD09A1 & MODIS band 1-7 surface reflectance & $500 \mathrm{~m}$ & 8-Day \\
MOD09CMG & MODIS band 1-7 surface reflectance & $0.05 \mathrm{Deg}$ & Daily \\
\hline
\end{tabular}

MOD09A1 data were collected to build the surface reflectance database in this article. The MOD09A1 dataset was the 8-day gridded product of the surface reflectance acquired by Terra after atmospheric, aerosol, and cirrus cloud correction and included seven bands covering the visible to NIR wavelengths at a spatial resolution of $500 \mathrm{~m}$. Research data were derived from the EOSDIS (Earth Observation Satellite Data and Information System) of NASA, which website address is https://search.earthdata.nasa.gov/search. Considering that the surface reflectance remains unchanged in a period of time $[19,24]$, four MOD09A1 images are produced in a month, where the pixel with the 
lowest surface reflectance is set as the pixel value using the minimum synthesis technique with the following equation:

$$
I(i, j)=\operatorname{Min}\left(I_{1}(i, j), I_{2}(i, j), I_{3}(i, j), I_{4}(i, j)\right)
$$

where $I$ is the composite imagery; $I_{1}, I_{2}, I_{3}$, and $I_{4}$ are the four MOD09A1 images in one month, respectively; and $i$ and $j$ are the row and column value, respectively, in an image.

Global MOD09A1 data from 2015 and 2016 were applied in this paper, which were preprocessed by projection transformation and mosaic to produce a $1 \mathrm{~km}$ spatial resolution via bidirectional linear interpolation. After vector clipping, the global land surface reflectance dataset of 2015-2016 was constructed via the method of minimum synthesis. Figure 2 is a true color composite image (RGB: band1, band4, band3) of a partial surface reflectance image in Asia $\left(34^{\circ}-50^{\circ} \mathrm{N}, 99^{\circ}-128^{\circ} \mathrm{E}\right)$ May 2015 using the LSR dataset for demonstration, which shows that the synthesized pixel is basically composed with clear pixel and can clearly present land cover types. Therefore, the constructed global LSR dataset can provide surface reflectance at a fixed spatial and temporal location $[25,26]$.

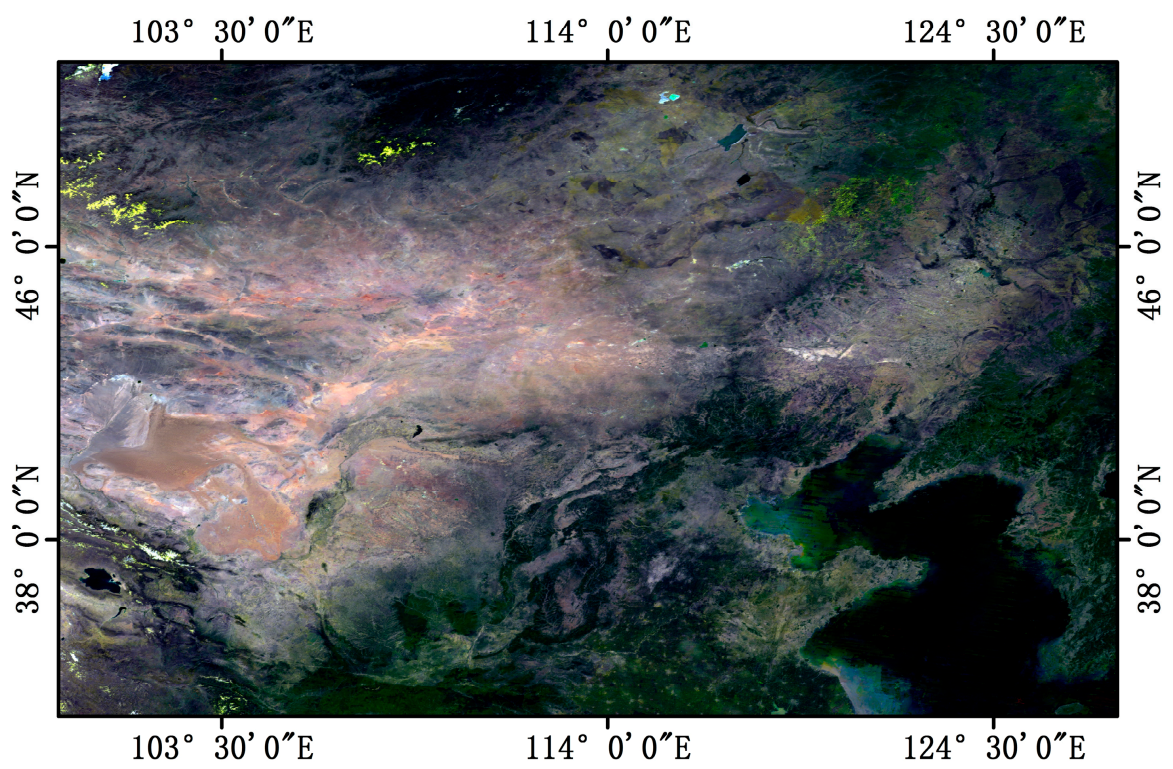

Figure 2. True color composite surface reflectance image in May 2015 using the LSR dataset.

\subsection{Dust Storm Remote Sensing Monitoring Supported by the LSR Dataset}

\subsubsection{MODIS Data}

MODIS captures data from 36 bands within the wavelength range of $0.4 \sim 14.4 \mu \mathrm{m}$ covering the visible, NIR, and TIR (thermal infrared) bands. With a bandwidth of $2330 \mathrm{~km}$, MODIS observes the Earth every 1-2 days at spatial resolutions of $250 \mathrm{~m}, 500 \mathrm{~m}$, and $1 \mathrm{~km}$. MODIS data have high temporal, spatial, and spectral resolution and can provide rich information for dust storm monitoring. According to the spectrum curves in Figure 1, bands 1, 3, 4, 6, and 7 in the visible, NIR, and SWIR (Short-wave Infrared) bands were used for dust storm monitoring. Table 2 shows the parameters of the chosen bands for MODIS.

Table 2. Parameters of the chosen bands for dust storm detection from MODIS.

\begin{tabular}{cccc}
\hline Band & Wavelength $(\boldsymbol{\mu m})$ & Central Wavelength $(\boldsymbol{\mu m})$ & Spatial Resolution \\
\hline 1 & $0.620 \sim 0.670$ & 0.645 & $250 \mathrm{~m} \times 250 \mathrm{~m}$ \\
3 & $0.459 \sim 0.479$ & 0.469 & $500 \mathrm{~m} \times 500 \mathrm{~m}$ \\
4 & $0.545 \sim 0.565$ & 0.555 & $500 \mathrm{~m} \times 500 \mathrm{~m}$ \\
6 & $1.628 \sim 1.652$ & 1.64 & $500 \mathrm{~m} \times 500 \mathrm{~m}$ \\
7 & $2.105 \sim 2.155$ & 2.13 & $500 \mathrm{~m} \times 500 \mathrm{~m}$ \\
\hline
\end{tabular}




\subsubsection{Dynamic Threshold Method}

The atmospheric radiation transfer equation indicates that, considering the aerosol model, the atmospheric and observation geometry are known factors, so the apparent reflectance can be obtained from the surface reflectance. In this study, MODIS bands 1, 3, 6, and 7 were simulated by inputting the parameters of surface reflectance, atmospheric model, AOD, observation geometry, aerosol type, etc. to the radiation transfer model 6S (Second Simulation of the Satellite Signal in the Solar Spectrum) to obtain the apparent reflectance of clear sky $[27,28]$. Table 3 shows the surface, atmospheric, and geometric parameters used for the simulation, etc. Figure 3 is a curve that simulates the maximum apparent reflectance of a satellite at a specific solar zenith angle and a satellite zenith angle, and the functional relation between LSR and apparent reflectance was computed from Equations (4)-(8).

Table 3. Surface, atmospheric, and geometric parameters used for the simulation.

\begin{tabular}{cc}
\hline Parameters & Parameter Setting \\
\hline Surface reflectance & $0.01,0.1: 0.1: 0.8$ \\
Aerosol optical depth & $0.00001,0.05: 0.05: 0.8$ \\
Solar zenith angle & $0: 6: 72$ \\
View zenith angle & $0: 6: 72$ \\
Relative azimuth angle & $0: 12: 180$ \\
Atmospheric model & Mrban model, Continental model, Maritime model, Desert model \\
Aerosol model & Mrditude summer, Midlatitude winter \\
\hline
\end{tabular}
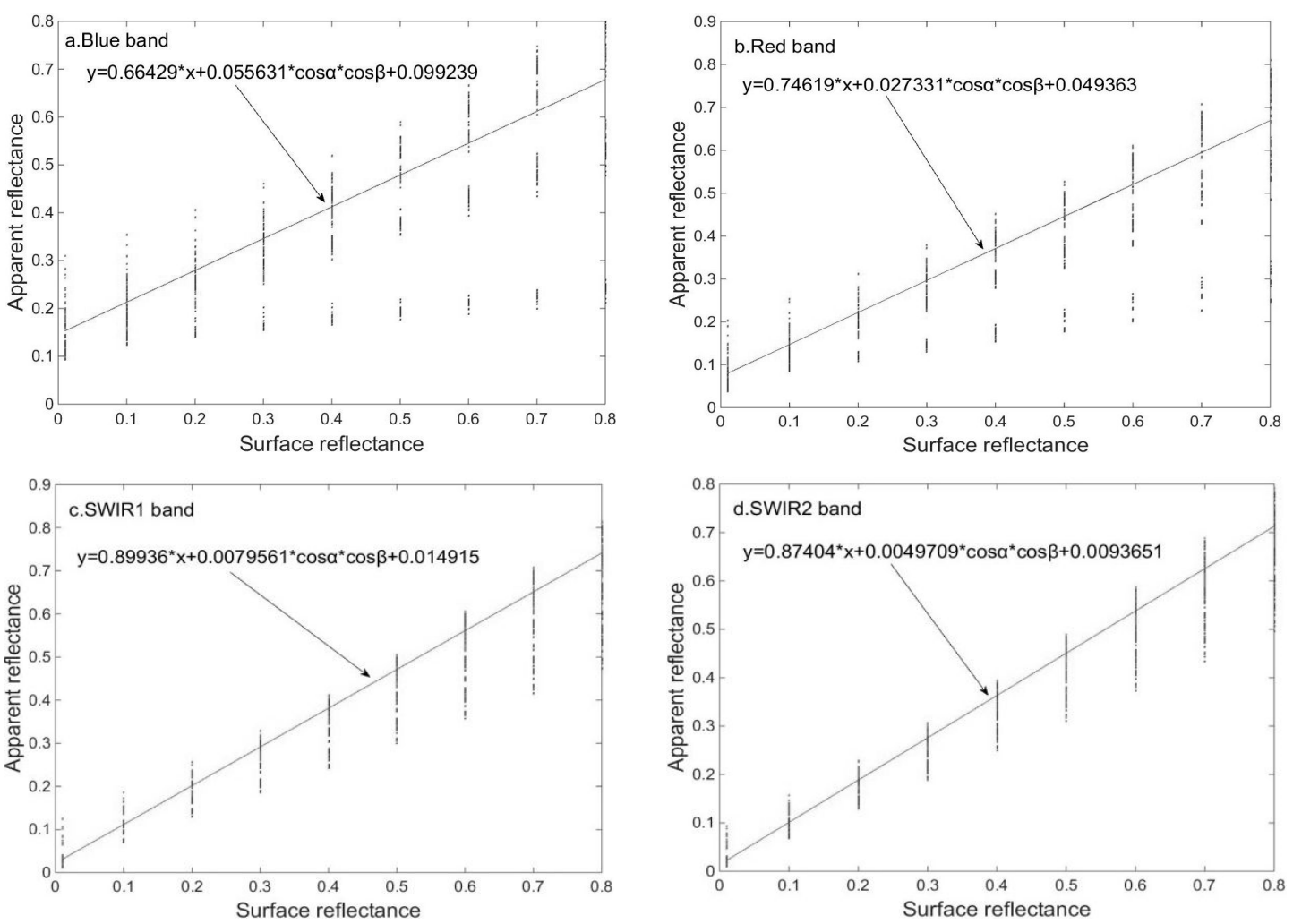

Figure 3. Relationships between the surface reflectance and apparent reflectance under different solar and satellite azimuth angles. (a) Blue band; (b) Red band; (c) SWIR1 band; (d) SWIR2 band.

According to atmospheric radiation transfer theory and the functional relation in Equations (1) and (2), the pixel surface reflectance from the LSR dataset was input into the equations for the derivation of the simulated apparent reflectance, which was then compared with real remote sensing imagery. A pixel was a dust pixel if the real apparent reflectance was larger than that of the simulated one, resulting in dynamic threshold identification for each pixel. 
Dust storm monitoring with the dynamic threshold method was performed via the following equations:

$$
\begin{aligned}
\rho_{B}^{* \prime} & =0.664 \cdot \rho_{B}+0.056 \cdot \cos \alpha \cos \beta+0.099 \\
\rho_{R}^{* \prime} & =0.746 \cdot \rho_{R}+0.027 \cdot \cos \alpha \cos \beta+0.049 \\
\rho_{\text {SWIR } 1}^{* \prime} & =0.899 \cdot \rho_{\text {SWIR } 1}+0.008 \cdot \cos \alpha \cos \beta+0.015 \\
\rho_{\text {SWIR } 2}^{* \prime} & =0.874 \cdot \rho_{\text {SWIR } 2}+0.005 \cdot \cos \alpha \cos \beta+0.009
\end{aligned}
$$

Dust pixel is identified by

$$
\begin{aligned}
& R_{i}=\rho_{i}^{*}-\rho_{i}^{* \prime}>0, i=B, R, S W R I 1, S W R I 2 \\
& R=R_{B} \cup R_{R} \cup R_{S W R I 1} \cup R_{S W I R 2}
\end{aligned}
$$

where $\rho_{i}^{* \prime}$ is the simulated apparent reflectance in different bands; $\rho_{i}$ is the surface reflectance; and $i$ is $B$ (Blue band, B3), $R$ (Red band, band1), SWRI1 (Short-wave Infrared1, band6), and SWRI2 (Short-wave Infrared2, band7). $\alpha$ and $\beta$ are the solar and satellite zenith angle; $\rho_{i}^{*}$ is the apparent reflectance; $R_{\mathrm{i}}$ is the dust detection result for each band; and $R$ is the final dust detection result. If the real apparent reflectance $\rho_{i}^{*}$ is larger than the simulated one $\rho_{i}^{* \prime}$, in other words, if $R_{i}$ is positive, the pixel is a dust pixel.

\subsubsection{Cloud Identification}

Cloud is commonly produced when dust storms occur. Cloud pixels are easily misidentified as dust pixels in dust storm monitoring using the dynamic threshold method, so it is necessary to separate possible cloud pixels. Figure 1 shows that cloud has high reflectance in the visible and NIR bands, where the third band of the blue band was the high value sector while the seventh band in the SWIR band was the low value sector. Therefore, cloud was identified using the negative reflectance difference of band 3 and band 7 [29-31]. The NDDI (Normalized Difference Dust Index) was built via normalization processing:

$$
N D D I=\left(\rho_{\text {SWIR2 }}^{*}-\rho_{B}^{*}\right) /\left(\rho_{\text {SWIR2 }}^{*}+\rho_{B}^{*}\right)
$$

where $\rho_{S W I R 2}^{*}$ and $\rho_{B}^{*}$ are the apparent reflectance of MODIS band 7 and band 3 . The pixel was identified as a dust pixel if NDDI $>0$, or was a cloud pixel.

\section{Results and Discussion}

Dust storms usually occur in the arid and semi-arid areas of the desert and its surrounding area in late winter and early spring [32-35]. North Africa, the Middle East, Middle and South Asia, East Asia, North America, and Australia are dust storm prone areas, where Western China is part of the Middle Asia dust storm prone area, and Northern China is part of the East Asia dust storm prone area [36-38]. To study dust storm monitoring using the dynamic threshold method, four dust storms that occurred on 27 March, 2015, 15 April, 2015, 4 March, 2016, and 5 May, 2016 in north and west China $\left(30^{\circ}-60^{\circ} \mathrm{N}\right.$, $90^{\circ}-130^{\circ} \mathrm{E}$ ) were monitored, and the results were verified by MICAPS data, and OMI AI data. Table 4 shows the time of the MODIS data obtained used for dust detected and the time of the validated data from MICAPS and the OMI AI. 
Table 4. Dust storm image and estimation data acquiring times.

\begin{tabular}{ccc}
\hline Imaging Time (UTC) & MICAPS Observing Time (UTC) & OMI AI Data Acquiring Time (UTC) \\
\hline 04:20 & $3: 00$ & $05: 14$ \\
27 March 2015 & 27 March 2015 & 27 March 2015 \\
03:15 & $03: 00$ & $04: 09$ \\
15 April 2015 & 15 April 2015 & 15 April 2015 \\
06:10 & $06: 00$ & $06: 56$ \\
04 March 2016 & 04 March 2016 & 04 March 2016 \\
03:00 & $03: 00$ & $03: 58$ \\
05 May 2016 & 05 May 2016 & 05 May 2016 \\
\hline
\end{tabular}

\subsection{Introduction to Validation Data}

MICAPS is a human-computer interaction system that supports weather forecast production. It processes kinds of meteorological information such as ground observation data, aerological sounding data, satellite cloud data, numerical forecast data, radar data, typhoon path data, urban forecast data, etc. MICAPS supports a medium-term, short-term, and instant weather forecast platform by retrieving various meteorological data, showing the meteorological graphics and images as well as the processing and editing images $[34,39,40]$.

Ground observation sites record ground and aerological sounding data every three hours including weather condition, visibility, wind direction and speed, atmospheric pressure and rainfall, etc. Table 5 shows the MICAPS dust weather codes for evaluating the monitoring results, based on which, dust data can be extracted for accuracy verification and results evaluation. As MODIS imagery has a wide range and large span, observation data captured at 11 am and $2 \mathrm{pm}$ (Beijing time), which are close to the imaging time, were adopted for the monitoring experiments.

Table 5. MICAPS code for dust weather.

\begin{tabular}{cccc}
\hline Code & Code Meaning & Code & Code Meaning \\
\hline 6 & Dust in suspension & 7 & Floating dust \\
8 & Dust devil & 9 & Dust storms \\
30 & Milddust storms weakened in the past hour & 31 & Mild dust storm \\
32 & Milddust storms enhanced in the past hour & 33 & Strong dust storms decreases in the past hour \\
34 & Strong dust storms & 35 & Strong dust storms enhanced in the past hour \\
\hline
\end{tabular}

OMI AI data obtained from sensor of OMI, which is one of the key sensors aboard the Aura with a resolution of $13 \mathrm{~km} \times 24 \mathrm{~km}$, realizing global Earth observation every day. The OMI has a wavelength of $270 \mathrm{~nm}-500 \mathrm{~nm}$, covering two UV (ultraviolet) channels, UV1 (270-310 nm) and UV2 $(310-365 \mathrm{~nm})$ as well as one visible channel VIS $(365-500 \mathrm{~nm})$. The AI (Aerosol Index) is defined as the residual of measured UV radiance and simulated radiation derived from equivalent reflectance [41]. The OMI near-UV aerosol algorithm (OMAERUV) calculates the Lambert Equivalent Reflectance (LER) at $388 \mathrm{~nm}\left(R_{388}^{*}\right)$ by assuming that the atmosphere scattering is purely Rayleigh, and the atmosphere is bounded by an opaque Lambert reflector [42]. The LER at $354 \mathrm{~nm}$ is calculated via $R_{388}^{*}$ :

$$
A I=-100 \log _{10}\left[\frac{I_{354}^{\text {obs }}}{I_{354}^{c a l c}\left(R_{354}^{*}\right)}\right]
$$

where $I_{354}^{o b s}$ is the radiation recorded by the remote sensor and $I_{354}^{\text {calc }}$ is the calculated LER value.

$\mathrm{AI}$ is the aerosol index for aerosols that can absorb UV radiation such as dust or smoke. The AI is close to 0 for cloud droplets or particles without absorption ability, or the AI is positive. AI is a good sand indicator that can provide strength and a range of information of absorptive dust aerosol and 
is positively correlated with AOD [41,43,44]. The OMI-Aura_L2-OMAERUV product was used to validate the sand monitoring results.

\subsection{Results Evaluation}

Figures 4-7 show the comparison among MODIS RGB image (image (a)), dust storm monitoring results (image (b)), MICAPS data (image (c)), and OMI AI data (image (d)).

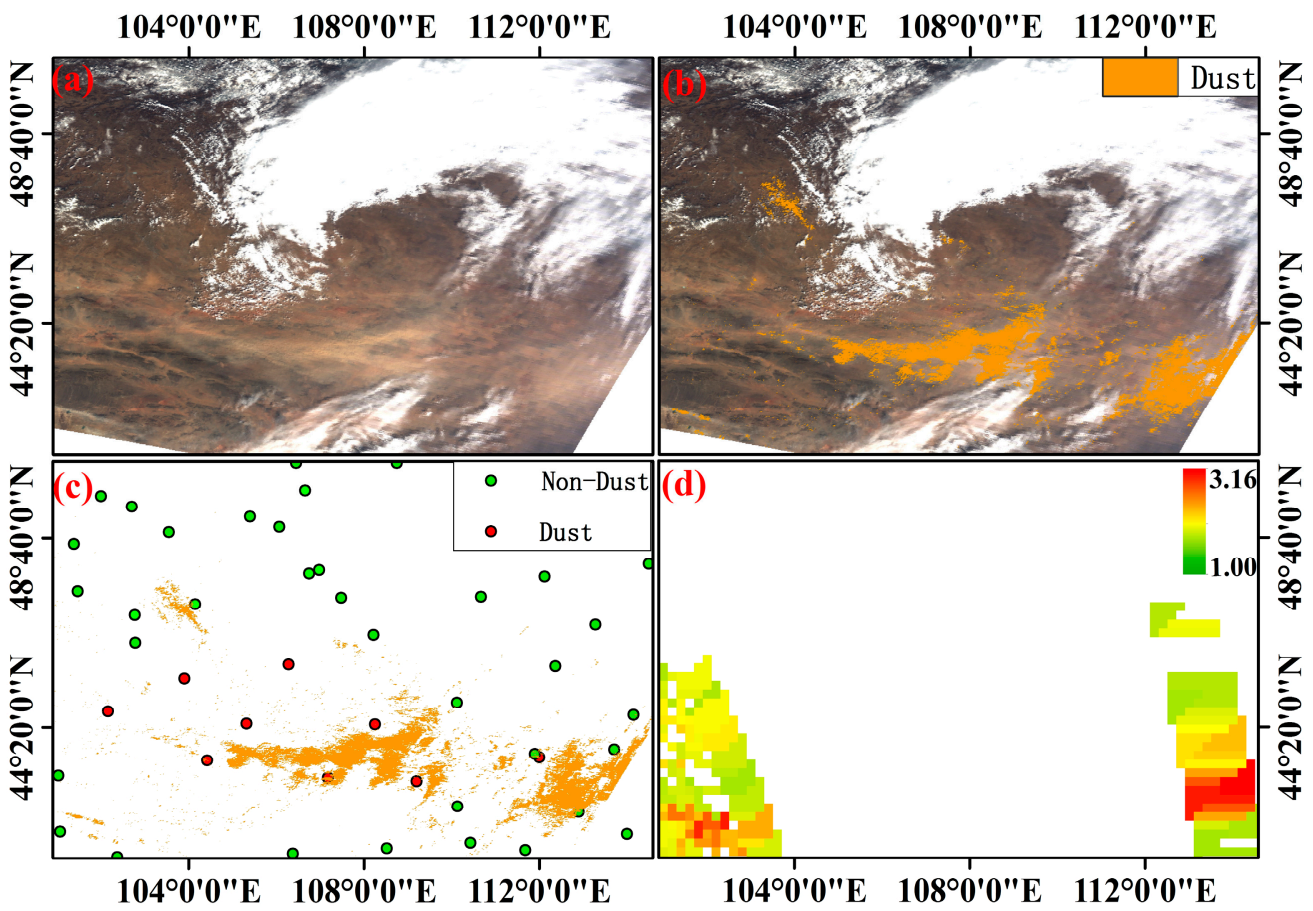

Figure 4. Comparison between the dust storm monitoring result (b), MODIS RGB image (a), MICAPS data (c), and OMI AI data (d) on 27 March, 2015.

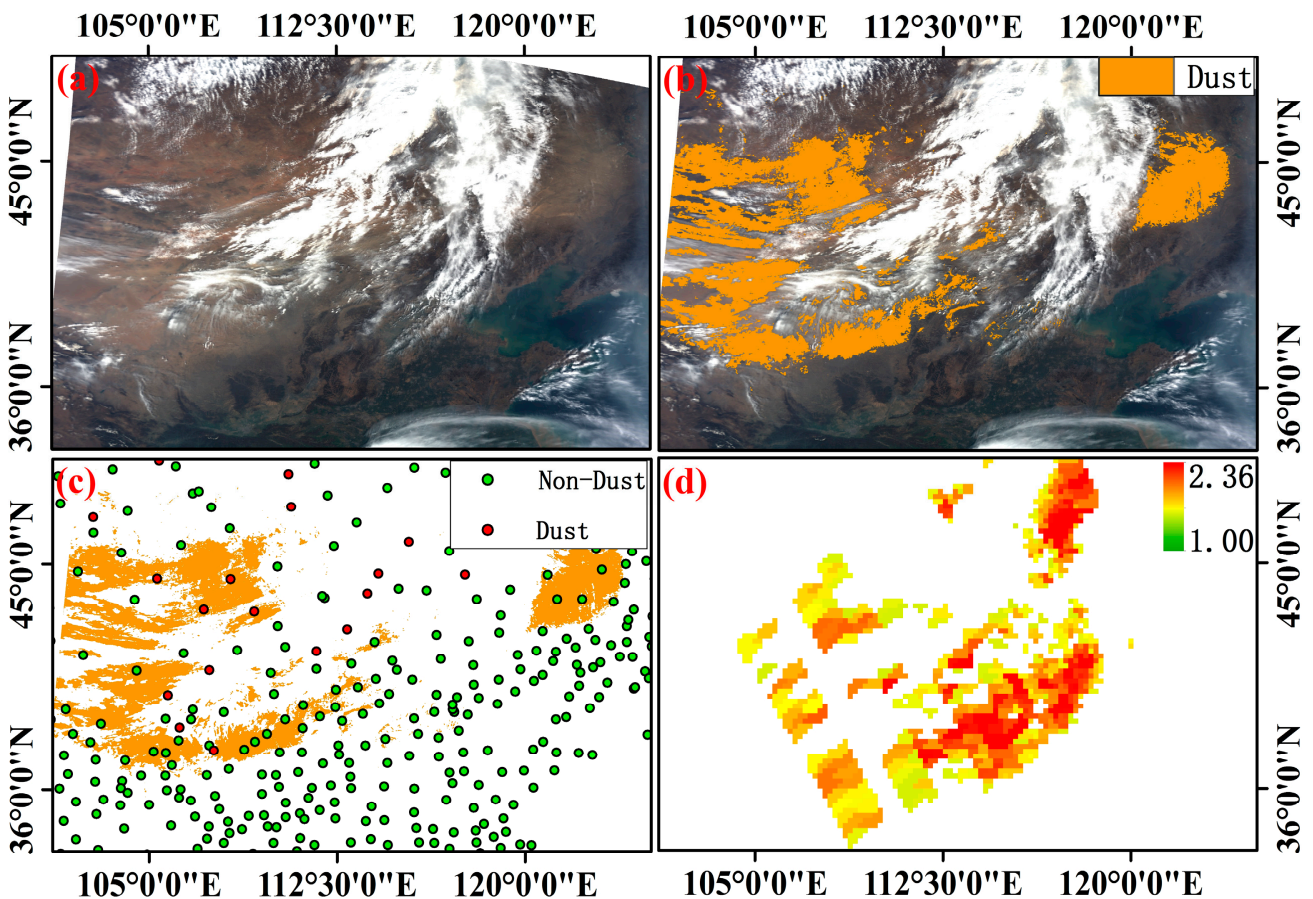

Figure 5. Comparison between the dust storm monitoring result (b), MODIS RGB image (a), MICAPS data (c), and OMI AI data (d) on 15 April, 2015. 


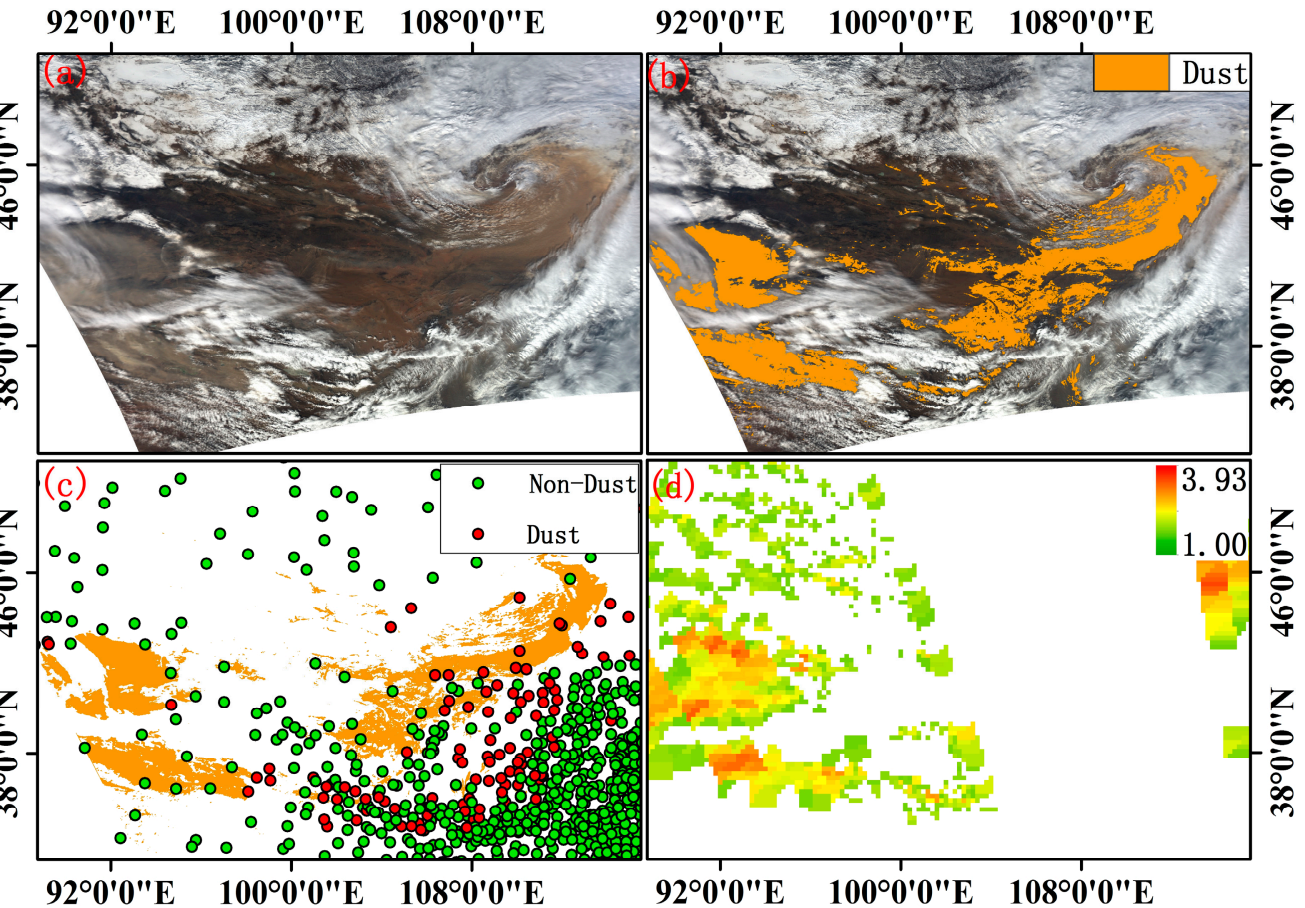

Figure 6. Comparison between the dust storm monitoring result (b), MODIS RGB image (a), MICAPS data (c), and OMI AI data (d) on 4 March, 2016.

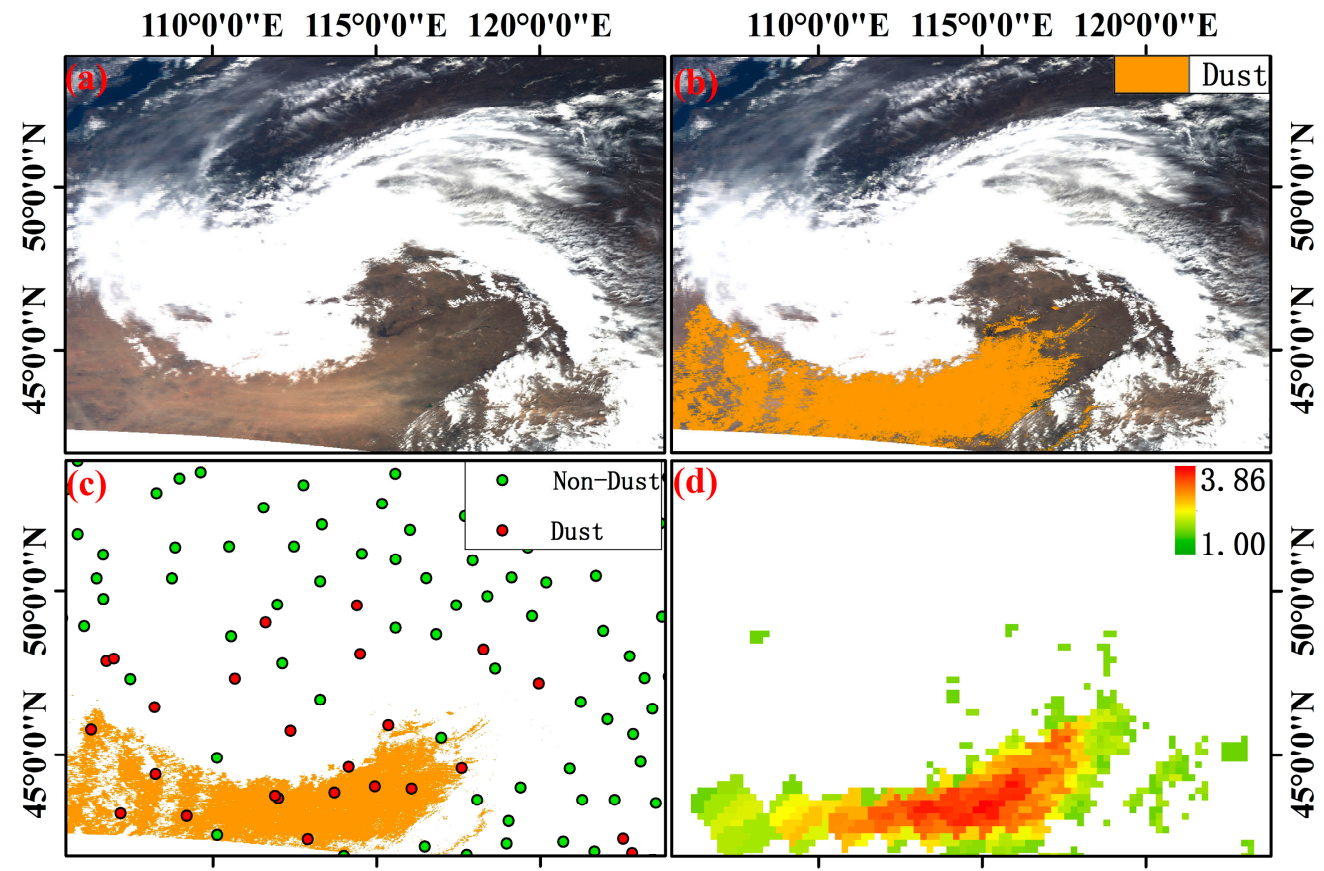

$110^{\circ} 0^{\prime} 0^{\prime \prime}$ E $115^{\circ} 0^{\prime} 0^{\prime \prime}$ E $120^{\circ} 0^{\prime} 0^{\prime \prime} \mathrm{E}$

$110^{\circ} 0^{\prime} 0^{\prime \prime} \mathrm{E} 115^{\circ} 0^{\prime} 0^{\prime \prime} \mathrm{E} 120^{\circ} 0^{\prime} 0^{\prime \prime} \mathrm{E}$

Figure 7. Comparison between the dust storm monitoring result (b), MODIS RGB image (a), MICAPS data (c) and OMI AI data (d) on 5 May, 2016.

Image (c) in Figures 4-7 shows the dust monitoring result of the MICAPS ground observation sites, where the red dots are the sites with a dust weather records and the blue dots are the sites with no dust weather records. The statistics show that there were 168 observation sites with dust weather records, 60 of which were in agreement with the monitoring results, and there were 106 sites covered with clouds and two without records, as shown in Table 6. The reason for the two observation sites 
without records was that the observing time was not consistent with the imagery acquiring time, so the dust region in the imagery was not the same as the observing data. A comparison with the MICAPS observation data indicated satisfactory accuracy for dust storm monitoring using the dynamic threshold method.

Table 6. Validation of the monitoring results with the MICAPS data.

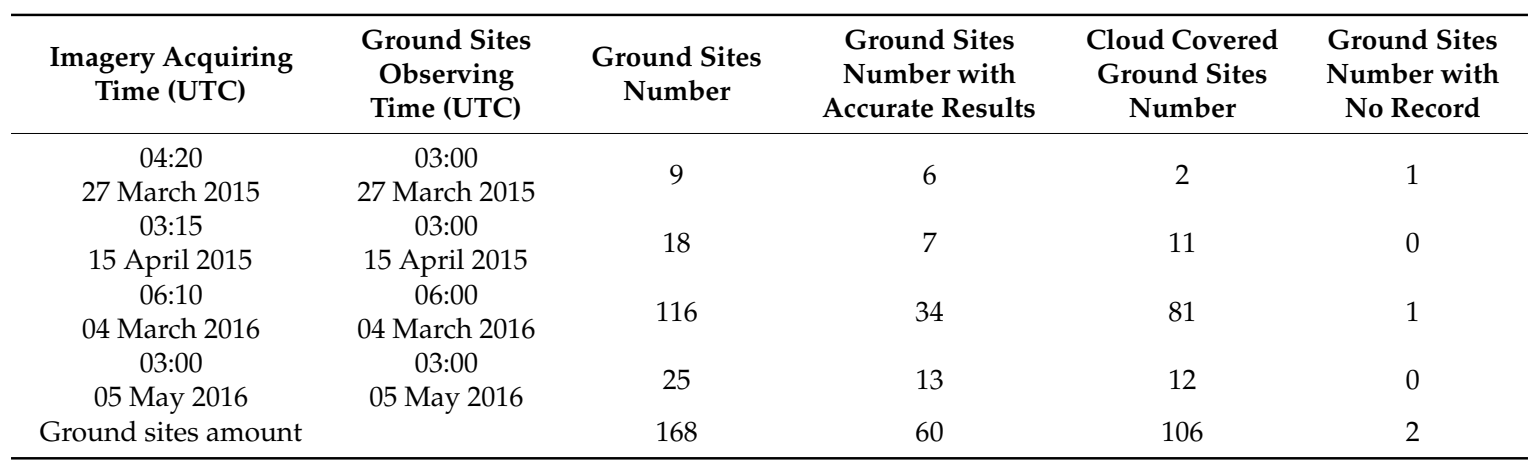

Image (d) in Figures 4-7 shows that the dust aerosol range from OMI AI was basically in common with the monitoring results, especially for the day on May 5, 2016. However, for the detection result of the other days, the spatial distribution was not completely consistent. The main reason is the difference of time and space scale. Table 3 reveals that the OMI AI imaging time was 46-60 min later than that of MODIS.

\section{Conclusions}

Conventional fixed threshold methods are easily affected by mixed pixels and atmospheric factors, resulting in poor monitoring results. This paper analyzed the spectral properties and mixed pixels of six typical land objects and proposed a dust storm monitoring method using dynamic threshold supported by the LSR dataset. The 8-day gridded MOD09 A1 data were used to build the global LSR dataset via minimum synthesis and then simulated the relations of surface reflectance and apparent reflectance via $6 S$ to realize pixel identification using the dynamic threshold. The method was applied to four dust storms, and the visual interpretation showed that the spatial distribution of the dust monitoring results were consistent with the true color composite images. The results showed that the dust monitoring results agreed well with the MICAPS observation stations data. The OMI AI validation was basically the same as the monitoring results. Although dust storm monitoring using the dynamic threshold acquired satisfactory results, the following problems still need to be solved in subsequent studies: (1) It assumes that the LSR remains the same in a period of time, while in fact, the LSR changes with natural and artificial factors; (2) dust information cannot be monitored completely because of cloud cover; and (3) the monitoring results of cloud edges, high reflectance land surface, and dust edges need to be improved.

Author Contributions: Q.S. conceived the research with the help of K.S and Y.M; K.S. and Q.S. wrote the paper; Y.M. performed the experiments and analyzed the results.

Funding: This research was funded by CHEOS (grant number 31-Y30B09-9001-13/15-11).

Acknowledgments: The authors thank to the National Aeronautics and Space Administration for providing the MODIS data, and thank to the China Meteorological Administration for providing MICAPS data.

Conflicts of Interest: The authors declare no conflicts of interest.

\section{References}

1. Jickells, T.D.; An, Z.S.; Andersen, K.K.; Baker, A.R.; Bergametti, G.; Brooks, N.; Cao, J.J.; Boyd, P.W.; Duce, R.A.; Hunter, K.A.; et al. Global iron connections between desert dust, ocean biogeochemistry, and climate. Science 2005, 308, 67-71. [CrossRef] [PubMed] 
2. Claquin, T.; Schulz, M.; Balkanski, Y.; Boucher, O. Uncertainties in assessing radiative forcing by mineral dust. Tellus B 1998, 50, 491-505. [CrossRef]

3. Solomon, S. IPCC (2007): Climate Change the Physical Science Basis. Am. Geophys. Union 2007, 9, $123-124$.

4. Zhao, T.X.P.; Ackerman, S.; Guo, W. Dust and Smoke Detection for Multi-Channel Imagers. Remote Sens. 2010, 2, 2347-2368. [CrossRef]

5. Stone, E.A.; Yoon, S.C.; Schauer, J.J. Chemical Characterization of Fine and Coarse Particles in Gosan, Korea during Springtime Dust Events. Aerosol Air Qual. Res. 2011, 11, 31-43. [CrossRef]

6. Tan, S.C.; Shi, G.Y.; Wang, H. Long-range transport of spring dust storms in Inner Mongolia and impact on the China seas. Atmos. Environ. 2012, 46, 299-308. [CrossRef]

7. Li, H.P.; Xiong, L.Y.; Zhuang, D.F. Research Progress and Future Development of Remote Sensing Monitoring on Sand-dust Disaster in China. Prog. Geogr. 2003, 22, 45-52.

8. Griggs, M. Measurements of atmospheric aerosol optical thickness over water using ERTS-1 data. J. Air Pollut. Control Assoc. 1975, 25, 622-626. [CrossRef]

9. Stowe, L.L.; Ignatov, A.M.; Singh, R.R. Development, validation, and potential enhancements to the second-generation operational aerosol product at the National Environmental Satellite, Data, and Information Service of the National Oceanic and Atmospheric Administration. J. Geophys. Res. Atmos. 1997, 102, 16923-16934. [CrossRef]

10. Amato, T.E.; Andrew, K.H.; Michael, J.P. Development of a new over-water Advanced Very High Resolution Radiometer dust detection algorithm. Int. J. Remote Sens. 2006, 27, 3903-3924.

11. Di, A.; Xue, Y.; Yang, X.; Leys, J.; Guang, J.; Mei, L.; Che, Y. Dust Aerosol Optical Depth Retrieval and Dust Storm Detection for Xinjiang Region Using Indian National Satellite Observations. Remote Sens. 2016, 8, 702. [CrossRef]

12. Yang, Y.K.; Sun, L.; Zhu, J.S.; Wei, J.; Su, Q.H.; Sun, W.X.; Liu, F.W.; Shu, M.Y. A simplified Suomi NPP VIIRS dust detection algorithm. J. Atmos. Solar-Terr. Phys. 2017, 164, 314-323. [CrossRef]

13. Roskovensky, K.J.; Liou, K.N. Differentiating airborne dust from cirrus clouds using MODIS data. Geophys Res Lett. 2005, 32, 12809. [CrossRef]

14. Miller, S.D. A consolidated technique for enhancing desert dust storms with MODIS. Geophys. Res. Lett. 2003, 30, 20. [CrossRef]

15. Zhang, P.; Lu, N.M.; Hu, X.Q.; Dong, C.H. Identification and physical retrieval of dust storm using three MODIS thermal IR channels. Glob. Planet. Change 2006, 52, 197-206. [CrossRef]

16. Ackerman, S.A. Remote sensing aerosols using satellite infrared observations. J. Geophys. Res. Atmos. 1997, 102, 17069-17079. [CrossRef]

17. Xu, H.; Cheng, T.; Gu, X.; Yu, T.; Wu, Y.; Chen, H. New Asia Dust Storm Detection Method Based on the Thermal Infrared Spectral Signature. Remote Sens. 2015, 7, 51-71. [CrossRef]

18. Matiellanovak, M.A.; Watson, M.I.; Delgadogranados, H.; Rose, W.I.; CárdenasGonzález, L.; Realmuto, V.J. Volcanic emissions from popocatépetl volcano, mexico, quantified using moderate resolution imaging spectroradiometer (modis) infrared data: A case study of the december 2000-January 2001 emissions. J. Volcanol. Geoth Res. 2007, 170, 76-85.

19. Sun, L.; Wei, J.; Wang, J.; Mi, X.; Guo, Y.; Lv, Y.; Yang, Y.; Gan, P.; Zhou, X.; Jia, C.; et al. A Universal Dynamic Threshold Cloud Detection Algorithm (UDTCDA) supported by a prior surface reflectance database. J. Geophys. Res. Atmos. 2016, 121, 7172-7196. [CrossRef]

20. Liu, Y.; Liu, R.; Cheng, X. Dust detection over desert surfaces with thermal infrared bands using dynamic reference brightness temperature differences. J. Geophys. Res. Atmos. 2013, 118, 8566-8584. [CrossRef]

21. She, L.; Xue, Y.; Yang, X.; Guang, J.; Li, Y.; Che, Y.; Fan, F.; Xie, Y. Dust detection and intensity estimation using Himawari-8/AHI observation. Remote Sens. 2018, 10, 490. [CrossRef]

22. Keshava, N.; Mustard, J.F. Spectral unmixing. IEEE Signal Process Mag. 2002, 19, 44-57. [CrossRef]

23. Chen, J.; Ma, L.; Chen, X.H.; Rao, Y.H. Research progress of spectral mixture analysis. J. Remote Sens. 2016, 20, 1102-1109.

24. Levy, R.C.; Mattoo, S.; Munchak, L.A.; Remer, L.A.; Sayer, A.M.; Patadia, F.; Hsu, N.C. The Collection 6 MODIS aerosol products over land and ocean. Atmos. Meas. Tech. 2013, 6, 2989-3034. [CrossRef]

25. Sun, L.; Sun, C.K.; Liu, Q.H.; Zhong, B. Aerosol optical depth retrieval by HJ-1/CCD supported by MODIS surface reflectance data. Sci. China Earth Sci. 2010, 53, 74-80. [CrossRef] 
26. Sun, L.; Yu, H.; Fu, Q.; Wang, J.; Tian, X.; Mi, X. Aerosol optical depth retrieval and atmospheric correction application for GF-1 PMS supported by land surface reflectance data. J. Remote Sens. 2016, 20, 216-228.

27. Vermote, E.F.; Tanré, D.; Deuze, J.L.; Herman, M.; Morcette, J.J. Second simulation of the satellite signal in the solar spectrum, 6S: An overview. IEEE Trans. Geosci. Remote Sens. 1997, 35, 675-686. [CrossRef]

28. Sun, L.; Wei, J.; Bilal, M.; Tian, X.; Jia, C.; Guo, Y.; Mi, X. Aerosol optical depth retrieval over Bright areas using landsat 8 OLI images. Remote Sens. 2016, 8, 23. [CrossRef]

29. Qu, J.J.; Hao, X.; Kafatos, M.; Wang, L. Asian Dust Storm Monitoring Combining Terra and Aqua MODIS SRB Measurements. IEEE Geosci. Remote Sens. 2006, 3, 484-486. [CrossRef]

30. Guo, N.; Cai, D.H.; Han, L.Y.; Liang, Y.; Li, M.X. Introduction to the Operational System and Identification Method of Dust Strom Based on MODIS. Meteorol. Mon. 2009, 35, 102-107.

31. Jafari, R.; Malekian, M. Comparison and evaluation of dust detection algorithms using MODIS Aqua/Terra Level 1B data and MODIS/OMI dust products in the Middle East. Int. J. Remote Sens. 2015, 36, 597-617. [CrossRef]

32. Sun, J.; Zhang, M.; Liu, T. Spatial and temporal characteristics of dust storms in China and its surrounding regions, 1960-1999: Relations to source area and climate. J. Geophys. Res. Atmos. 2001, 106, 10325-10333. [CrossRef]

33. Tsolmon, R.; Ochirkhuyag, L.; Sternberg, T. Monitoring the source of trans-national dust storms in north east Asia. Int. J. Digit Earth. 2008, 1, 119-129. [CrossRef]

34. Fang, L.; Wang, S.; Yu, T.; Gu, X.; Zhang, X.; Wang, W.; Ren, S. Changes in Aerosol Optical and Micro-Physical Properties over Northeast Asia from a Severe Dust Storm in April 2014. Remote Sens. 2016, 8, 394. [CrossRef]

35. Su, Q.; Sun, L.; Yang, Y.; Zhou, X.; Li, R.; Jia, S. Dynamic Monitoring of the Strong Sandstorm Migration in Northern and Northwestern China via Satellite Data. Aerosol Air Qual. Res. 2017, 17, 3244-3252. [CrossRef]

36. Huang, J.; Ge, J.; Weng, F. Detection of Asia dust storms using multisensor satellite measurements. Remote Sens. Environ. 2007, 110, 186-191. [CrossRef]

37. Fu, P.; Zhong, S.; Huang, J.; Song, G. An observational study of aerosol and turbulence properties during dust storms in northwest China. J. Geophys. Res. Atmos. 2012, 117, 1-12. [CrossRef]

38. Luo, J.N.; Xu, Z.; Qi, Y.G. Global dust remote sensing with the Feng Yun-3 satellite. J. Desert Res. 2015, 35, 690-698.

39. Luo, B.; Tan, X.; Guo, Y. Introduction of MICAPS-A Chinese forecaster's interactive system. In Proceedings of the 86th AMS Annual Meeting/8th Conference on Atmospheric Chemistry, Atlanta, GA, USA, 27 January-3 February 2006.

40. Huang, X.X.; Wang, T.J.; Jiang, F.; Liao, J.B.; Cai, Y.F.; Yin, C.Q.; Zhu, J.L.; Han, Y. Studies on a severe dust storm in East Asia and its impact on the air quality of Nanjing, China. Aerosol Air Qual. Res. 2013, 13, 179-193. [CrossRef]

41. Kaskaoutis, D.G.; Nastos, P.T.; Kosmopoulos, P.G.; Kambezidis, H.D.; Kharol, S.K.; Badarinath, K.V.S. The Aura-OMI Aerosol Index distribution over Greece. Atmos. Res. 2010, 98, 28-39. [CrossRef]

42. Torres, O.; Tanskanen, A.; Veihelmann, B.; Ahn, C.; Braak, R.; Bhartia, P.K.; Veefkind, P.; Levelt, P. Aerosols and surface UV products from Ozone Monitoring Instrument observations: An overview. J. Geophys. Res. Atmos. 2007, 112, 1-14. [CrossRef]

43. Hsu, N.C.; Herman, J.R.; Torres, O.; Holben, B.N.; Tanre, D.; Eck, T.F.; Smirnov, A.; Chatenet, B.; Lavenu, F. Comparisons of the TOMS aerosol index with Sun-photometer aerosol optical thickness: Results and applications. J. Geophys. Res. Atmos. 1999, 104, 6269-6279. [CrossRef]

44. Kaskaoutis, D.G.; Kambezidis, H.D.; Nastos, P.T.; Kosmopoulos, P.G. Study on an intense dust storm over Greece. Atmos. Environ. 2008, 42, 6884-6896. [CrossRef]

(C) 2019 by the authors. Licensee MDPI, Basel, Switzerland. This article is an open access article distributed under the terms and conditions of the Creative Commons Attribution (CC BY) license (http://creativecommons.org/licenses/by/4.0/). 